\title{
PERCEPÇÃO DOS ESTUDANTES DA EAD DO CURSO DE CIÊNCIAS CONTÁBEIS SOBRE A DISCIPLINA "EXAME DE SUFICIÊNCIA DO CRC
}

\author{
SÃO PAULO/SP MAIO/2018 \\ $\begin{array}{cc}\text { Lourdes Souza Utrilla da Silva } & \text { - UAM - lourdes.utrilla@uol.com.br } \\ \text { Marcelo Lima Alves } & \text { - UAM - marcelomla36@gmail.com } \\ \text { Vilma A. Frois Lima Alves } & \text { - UNP - vilmafrois@yahoo.com.br } \\ \text { Priscilla Silva Silvestrin } & \text { - UNIFACS - prisilvestrin@gmail.com }\end{array}$
}

Tipo: Relato de Experiência Inovadora (EI)

Categoria: Pesquisa e Avaliação

Setor Educacional: EDUCAÇÃO SUPERIOR

\begin{abstract}
RESUMO
Este artigo traz uma experiência sobre a implementação e manutenção da disciplina "Exame de suficiência do CRC" em uma instituição de ensino superior privada, sediada na cidade de São Paulo. O objetivo principal é conhecer a percepção dos estudantes da EaD sobre a usabilidade da disciplina "Exame de suficiência do CFC" ofertada no curso de ciências contábeis. Para alcançar o objetivo proposto, foi disponibilizado aos estudantes da disciplina um link do questionário, com questões fechadas a abertas no ambiente virtual de aprendizagem e por meio do correio eletrônico. Espera-se com os resultados obtidos, contribuições teóricas e práticas para os atores envolvidos no curso de ciências contábeis, bem como, repensar sobre a melhor forma de preparar os estudantes para o exame de suficiência do CFC. A pesquisa resultou em maciça aprovação dos estudantes respondentes com relação à manutenção da disciplina, para prepará-los para a realização do exame de suficiência do CFC, e também para o mundo do trabalho, considerando que poderá servir como apoio na preparação, também para concursos públicos na área contábil, e outros testes que possam se submeter, devido à base teórica de discussão que abrange diversos temas. Como sugestão à Instituição de ensino estudada, é importante que a mesma certifique se a disciplina está liberada para todos os estudantes do curso de ciências contábeis, bem como, reforçar a comunicação com todos os estudantes, no sentido de que os mesmos conheçam e acessem este artefato de apoio aos seus estudos, com relação ao exame de suficiência do CFC.
\end{abstract}

Palavras-chave: Exame de Suficiência do CFC; Educação a distância e Ciências contábeis. 


\section{INTRODUÇÃO}

Com a globalização foi necessária a harmonização das normas brasileiras aos padrões internacionais, visando maior transparência e qualidade das informações contábeis. Assim, em 2007 foi sancionada a lei 11.638/07, que trouxe diversas alterações na Lei 6.404/76 (Lei das Sociedades por Ações) que estava em vigor há 30 anos na contabilidade brasileira. Com a nova lei, a função do contador valorizou e passou a ser considerada a principal linguagem no mundo dos negócios, exigindo mudanças na postura dos profissionais envolvidos nas elaborações, análise e publicações das demonstrações contábeis.

No Brasil para um profissional exercer a profissão de contador, é preciso estar registrado no Conselho Regional de Contabilidade do seu Estado, para isso existe a obrigatoriedade de aprovação no exame de suficiência.

Em 1999 o exame de suficiência passou a ser obrigatório para a obtenção de Registro Profissional na profissão o Conselho Federal de Contabilidade (CFC), conforme a Resolução CFC no 853/99, que vigorou de 2000 até 2005, quando foi extinto por medida judicial, sendo realizados dois exames por ano. Durante esse período, foi reconhecido como um instrumento eficaz de capacitação técnica no país, no sentido de incentivar o aprimoramento do ensino de contabilidade. O exame voltou a ser exigido conforme resolução 12.249 de 2010, a partir do primeiro semestre de 2011 (Gonzales \& Ricardino Filho, 2017).

O Exame é aplicado duas vezes por ano, e para ser aprovado, o candidato precisa alcançar, no mínimo, $50 \%$ dos pontos possíveis na prova, conforme o artigo $5^{\circ}$ da Resolução CFC no 853/99. A prova é uma tentativa do CFC de suprir possíveis deficiências por parte das instituições de ensino (Bulgarim, Rodrigues, Pinho \& Machado, 2014).

Considerando a contextualização ora descrita, essa pesquisa surgiu da percepção de que existe a necessidade de oferecer aos estudantes, ainda durante o curso de ciências contábeis, materiais de apoio para prepará-los gradativamente para a realização do exame de suficiência, principalmente considerando os elevados índices de reprovações nos exames anteriores, sendo: 2015/1(45,52\%), 2015/2 (85,32\%), 2016/1 (58,14\%), 2016/2 (78,11\%), 2017/1 (74,74\%) e 2017/2 (72,98\%).

O estudante, ao iniciar um curso superior possivelmente tem a pretensão de se preparar para atuar no mundo do trabalho e na profissão desejada. Assim, para o seu posterior 
ingresso no mercado de trabalho, o ensino superior tem um papel essencial, que consiste no fato de que "o método utilizado pelo professor no processo de ensino aprendizagem é de fundamental importância para o sucesso do aluno" (Marion, Garcia e Cordeiro, 1999, p. 28). Além disso, Dias (2009, p. 38), afirma que no processo de ensino e aprendizagem "deve haver a aquisição de um conjunto de conhecimentos, técnicas e métodos de forma crítica por parte do aluno". Assim, o professor deve ser o mediador entre o estudante e o processo de ensino aprendizagem.

Com as alterações na legislação que envolve a área contábil, a globalização e as exigências do mundo do trabalho para a área contábil, as instituições de ensino superior estão se aprimorando para preparar seus estudantes para a atuação no campo profissional (Bonifácio e Callegari, 2012).

Assim, em 2015, com a preocupação concatenar a tecnologia com a prática, buscando otimizar o processo de aprendizagem na IES estudada, foi criada uma disciplina denominada "Exame de suficiência do CRC", ofertada na modalidade a distância, para todos os estudantes matriculados no curso de ciências contábeis da Instituição de ensino estudada, tanto para o presencial quanto para a Educação a Distância (EaD).

Trata-se de uma disciplina não avaliativa, sem custo para os estudantes, segregada em oito unidades de estudos (1-Estrutura das demonstrações contábeis, 2-Contabilidade do setor público, 3- Contabilidade Geral, 4-Contabilidade de Custos, 5-Contabilidade Tributária, 6-Contabilidade Societária, 7-Métodos quantitativos e 8-Auditoria e Perícia). Esta disciplina tem por objetivo preparar os estudantes gradativamente, no decorrer do curso, para a realização com sucesso do exame de suficiência do CFC.

Nos materiais da disciplina contém vídeos, provas realizadas em anos anteriores, com os devidos comentários e orientações com resoluções passo a passo, fórum fale com o professor e webconferências. Nesse contexto, este estudo intenta apresentar uma experiência de implementação e manutenção da disciplina "Exame de suficiência do CRC" em uma instituição de ensino superior privada, sediada na cidade de São Paulo.

Assim, surgiu a seguinte questão de pesquisa: Qual é a percepção dos estudantes da EaD sobre a disciplina "Exame de suficiência do CRC" do curso de ciências contábeis?

Nesse contexto, a presente pesquisa tem por objetivo descrever a percepção dos estudantes do Curso de Ciências Contábeis sobre a disciplina Exame de suficiência do CRC. Esta pesquisa é importante por tratar-se de um assunto relevante e atual que 
causa impacto aos estudantes, aos professores e as instituições de ensino.

\section{REFERENCIAL TEÓRICO}

Considerando-se as necessidades de mercado que envolve os profissionais do mundo contábil, que exige conhecimento, competitividade e inovação, as instituições de ensino superior encontram-se pressionadas a atender a demanda de qualificar adequadamente os estudantes para atuação na área.

Para Fonteles, Oliveira e Almeida (2011, p. 2), as "mudanças na contabilidade geram, por consequência, mudanças no ensino da ciência contábil". Os autores ainda complementam "que os alunos em formação nas universidades serão os futuros profissionais atuantes nos mais variados ramos do mercado".

Os resultados dos exames anteriores, apresentaram baixo índice de aprovação dos estudantes, conforme os relatórios estatísticos divulgados pelo CFC de 2011 até 2017, conforme figura 1:

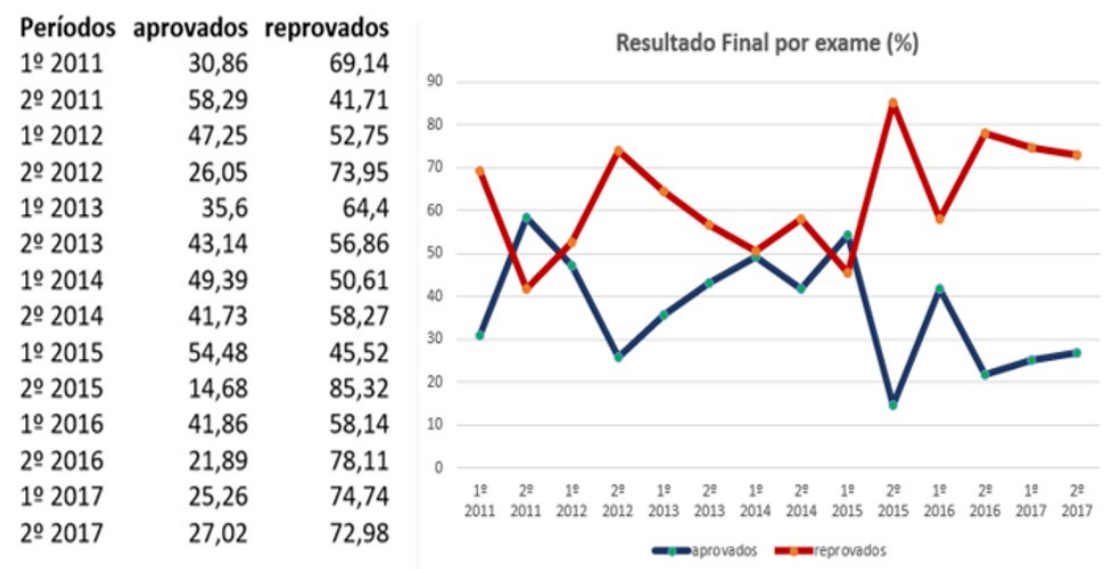

Figura 1. Representação do resultado final por exame

Fonte:http://cfc.org.br/registro/exame-de-suficiencia/relatorios-estatisticos-do-exame-desuficiencia

Tostes (2008) pesquisou sobre o exercício da profissão contábil na França, no Brasil e Estados Unidos da América. Concluiu que: na França, para o profissional exercer plenamente a profissão precisa ser formado (provas, estágio e defesa pública de tese), nos EUA a formação é rigorosa, mas pode ser em curto espaço de tempo, dependendo da situação individual. No Brasil é aceito como pré-requisito o conhecimento básico fornecido no curso de graduação sem levar em conta a qualidade variável das 
faculdades.

Neste contexto, no Brasil sabe-se que o nível de conhecimento do contador recémformado pode ser mensurado por meio do exame de suficiência do CFC, exigido para o exercício da profissão.

A figura 2 apresenta o ranking da apuração de resultado geral por IES, referente as principais instituições de ensino localizadas no município de São Paulo e grande São Paulo:

\begin{tabular}{|c|c|c|c|c|c|}
\hline \multirow{2}{*}{\multicolumn{2}{|c|}{$\begin{array}{l}\text { Principais IES do estado de São } \\
\text { Paulo }\end{array}$}} & \multicolumn{2}{|c|}{ 2017-2 } & \multicolumn{2}{|c|}{ 2017-1 } \\
\hline & & \multirow{2}{*}{$\frac{\text { Qtde. }}{50}$} & \multirow{2}{*}{$\begin{array}{c}\text { \% Aprovados } \\
94,87 \\
\end{array}$} & \multirow{2}{*}{$\frac{\text { Qtde. }}{48}$} & \multirow{2}{*}{$\begin{array}{c}\% \text { Aprovados } \\
97,50 \\
\end{array}$} \\
\hline 19 & USP - SP & & & & \\
\hline $2^{\circ}$ & TREVISAN & 77 & 67,65 & 84 & 68,83 \\
\hline $3^{\circ}$ & FECAP & 64 & 66,04 & 59 & 69,23 \\
\hline $4 \div$ & UNIVERSIDADE SÃO JUDAS & 119 & 63,73 & 226 & 65,83 \\
\hline $5^{\circ}$ & PUC-SP & 58 & 58,52 & 58 & 54,90 \\
\hline $6=$ & ANHEMBI MORUMBI & 165 & 57,97 & 159 & 43,07 \\
\hline $7^{\circ}$ & MACKENZIE SP & 103 & 57,95 & 70 & 73,77 \\
\hline $8^{\circ}$ & SENAC - SP & 71 & 47,69 & 64 & 53,57 \\
\hline $9^{\circ}$ & UNIP SP & 1.104 & 38,90 & 1.113 & 39,56 \\
\hline $10^{\circ}$ & UNICSUL & 187 & 34,76 & 214 & 38,32 \\
\hline $11^{\circ}$ & UNIITALO - SP & 129 & 31,48 & 136 & 18,92 \\
\hline $12^{\circ}$ & FMU - SP & 227 & 31,38 & 216 & 29,26 \\
\hline $13^{\circ}$ & UNIVERSIDADE METODISTA & 123 & 31,00 & 126 & 37,14 \\
\hline $14^{\circ}$ & UNINOVE & 1.008 & 25,90 & 1.006 & 27,42 \\
\hline $15^{\circ}$ & UNISA & 123 & 24,24 & 162 & 16,54 \\
\hline $16^{\circ}$ & SUMARÉ - SP & 109 & 23,71 & 84 & 20,00 \\
\hline $17^{\circ}$ & UNIVERSIDADE GUARULHOS & 162 & 23,53 & 208 & 29,63 \\
\hline $18^{\circ}$ & ANHANGUERA - SP & 167 & 23,19 & 214 & 20,11 \\
\hline $19^{\circ}$ & FLAMINGO - SP & 84 & 21,62 & 85 & 16,46 \\
\hline $20^{\circ}$ & UNICID & 165 & 20,83 & 232 & 20,79 \\
\hline $21 \%$ & FACULDADE DRUMMOND & 127 & 17,86 & 134 & 18,25 \\
\hline $22^{\circ}$ & UNIESP & 154 & 12,78 & 185 & 14,02 \\
\hline
\end{tabular}

Figura 2. Ranking da apuração de resultado geral por IES do município de São Paulo e grande São Paulo

Fonte:http://cfc.org.br/registro/exame-de-suficiencia/relatorios-estatisticos-do-exame-desuficiencia

O índice médio de aprovação do exame realizado no segundo semestre de 2017 foi de $27,02 \%$. Uma da IES que pertence ao grupo pesquisado encontra-se com índice acima de $57 \%$ de aprovação.

\section{METODOLOGIA}

Este estudo tem caráter descritivo e abordagem qualitativa. De acordo com Cervo, Bervian e Silva (2007), a pesquisa descritiva observa, registra, analisa e correlaciona os fatos ou fenômenos (variáveis) sem manipulá-los. Procura descobrir, com maior precisão possível, a frequência com que um fenômeno ocorre, sua relação e conexão 
com outros, sua natureza e suas características. Segundo Raupp e Beuren (2006, p. 92), "na pesquisa qualitativa concebem-se análises mais profundas em relação ao fenômeno que está sendo estudado".

Este estudo pesquisou a opinião de estudantes do curso de ciências contábeis do ensino a distância, por meio de uma amostra não-probabilística e foi realizado em uma instituição de ensino superior privada, sediada na cidade de São Paulo, que pertence à um grupo econômico de uma Universidade de grande porte.

A população dessa pesquisa foi composta por todos os estudantes da EaD, ativos e matriculados no curso de ciências contábeis da instituição de ensino pesquisada. Representando, neste caso, um censo (Megliorini, Weffort \& Holanda, 2004).

Os dados foram coletados por meio do software Lime Survey. O link do questionário, com questões fechadas a abertas, foi enviado para os estudantes no ambiente virtual de aprendizagem por meio do correio eletrônico. Os dados foram coletados no período de janeiro a março de 2018 e em seguida, foram mapeados numa planilha. O questionário foi encaminhado para 1990 discentes e destes 233 foram respondidos, significando $12 \%$ do total.

\section{RESULTADOS}

Quanto ao perfil dos 233 respondentes, 84 (36\%) estão cursando o primeiro ano, 43 (18\%) estão no segundo ano e 106 (45\%) no terceiro e último ano. No que diz respeito a faixa etária, $60(26 \%)$ até 25 anos, 94 (40\%) entre 26 a 35 anos, seguido de $58(25 \%)$ com idades entre 36 a 45 anos e 21 (9\%), acima de 46 anos.

Os discentes reconheceram que a disciplina "exame de suficiência do CRC", efetivamente os ajuda a se sentirem preparados para o campo profissional da área contábil, pois, dos 233 estudantes, 100 (43\%) sentem-se totalmente preparados e 118 $(51 \%)$ parcialmente preparados e somente, 15 (6\%), declaram-se despreparados.

Ao analisar as declarações escritas nas questões abertas, que indagou o motivo deste sentimento da falta de preparação, encontrou-se alegações como: "o conhecimento na modalidade EaD traz a responsabilidade do aluno buscar seu próprio conhecimento", ou "Por estar apenas no início do curso, sei que ainda tenho muito o que absorver de conteúdo para atuar na área”. Outros sentem falta do contato presencial como "(...) pela ausência do contato mais próximo ou eficiente, ao professor e também com os colegas". Já outros alegam que precisam de mais dedicação aos estudos como "Minha 
responsabilidade: não tenho feito os simulados disponíveis por falta de tempo", e "Não estou tendo tempo suficiente para me preparar para a prova".

Quando perguntado na pesquisa, o que a universidade poderia oferecer como material de apoio, identificou-se sugestões para a disponibilização de um recurso com o formato já existente, o que evidenciou que estes estudantes estão sem acesso ou desconhecem este artefato já disponível na $\mathrm{EaD}$, conforme alguns comentários: "Disponibilizar material voltado para a realização do exame, obter dicas dos professores e ofertar uma disciplina para preparação com resolução de questões". "Inserir no sistema uma disciplina extracurricular exclusiva para o Exame de Suficiência já no início da graduação"; "Treinamentos específicos, com questões anteriores, acredito que assim teríamos o feeling do exame"; "Promover mais cursos complementares gratuitos e atividades focadas no exame de suficiência"; "Disponibilizar cursos gratuitos sobre as questões relacionadas ao exame de suficiência do CFC"; "Disponibilizar materiais específicos, com questões de exames anteriores, acredito que assim teríamos preparo para o exame"; "Falta uma disciplina com simulados voltados para o exame".

Este estudo ainda questionou quanto ao prazo que o discente pretende realizar a prova do CFC a fim de buscar a habilitação profissional do contador, e identificou-se que a maioria, $186(80 \%)$ estudantes responderam "imediatamente" e 25 (11\%) "em 6 meses", já $11(5 \%)$ pretendem submeter-se à referida avaliação após 1 ano.

Os dados da pesquisa destacaram, que de 11 estudantes que se submeteram ao referido exame, mesmo antes da finalização de seu curso, 9 (82\%) foram aprovados e 2 (18\%) reprovados. Este dado pode solidificar o resultado que o ensino a distância se propõe, ou seja, preparar os estudantes para alcançar um desempenho satisfatório mediante submissão do exame e o sucesso no mundo de trabalho.

Vale ressaltar um depoimento de uma discente que publicou no fórum fale com o professor da disciplina "Exame de suficiência do CRC" a sua declaração de experiência de sucesso para motivar os outros estudantes da sua sala de aula virtual: "Prestei $o$ exame de suficiência do CFC neste $1^{\circ}$ semestre de 2017, e fui aprovada. Acabo de passar para o $8^{\circ}$ semestre do curso EaD em Contábeis. Para quem for fazer a prova: vale a dica, eu estudei somente pelas questóes de provas passadas do material disponibilizado na disciplina exame de suficiência. Se tinha dúvida em alguma questão, procurava alguém para me ajudar. Nada de ficar pegando livros, etc. Somente pelas questões - fiz TODAS mais de uma vez cada prova e consegui 30 pontos de 50, e ainda não tinha iniciado o $7^{\circ}$ semestre do curso aqui!" 
Conforme os dados da pesquisa e reforçado pelas declarações dos estudantes, evidenciou-se que os discentes com acesso à disciplina, utilizam e aprovam a oferta e a sua estrutura como artefato de apoio aos seus estudos para o exame de suficiência e os que não se sentem totalmente preparados não culparam a IES no diz respeito a qualidade da metodologia de ensino aplicada na sua preparação.

\section{CONCLUSÕES}

A pesquisa resultou em maciça aprovação dos estudantes respondentes com relação à manutenção da disciplina Exame de suficiência do CRC, não apenas para prepará-los para a realização do exame de suficiência, mas também para o mundo do trabalho, considerando que poderá servir também como apoio na preparação para concursos públicos na área contábil, e outros testes que possam se submeter devido à base teórica de discussão que abrange diversos temas.

O resultado alcançado de certa forma era esperado, mas existe a necessidade de uma validação empírica, que foi proporcionada neste estudo.

Este trabalho pode ajudar os atores envolvidos no curso de ciências contábeis, quanto a reflexão sobre a melhor forma de preparar os estudantes para o exame de suficiência do CFC.

Como sugestão à Instituição de ensino estudada, os pesquisadores sugerem reforçar a comunicação com os estudantes para que os mesmos conheçam e acessem este artefato de apoio aos seus estudos e concentrar esforços para a manutenção da disciplina em todas as IES do grupo.

\section{REFERÊNCIAS:}

Bonifácio, R.; Callegari, O. M. (2012). O exame de suficiência contábil e a percepção dos professores do curso de ciências contábeis. In: XII Colóquio Internacional sobre Gestão Universitária nas Américas. Anais.Vera Cruz-México.

Bulgarim, M. C. C., Rodrigues L. L., Pinho J. C. C. \& Machado D. Q. (2014). O desempenho dos profissionais de contabilidade no exame de suficiência do CFC: uma análise de conglomerados regionais. Revista de contabilidade e organizações. 61-71

Cervo, A. L; Bervian, P. A; SILVA, R. (2007). Metodologia científica. 6. ed. São Paulo: Pearson. 
Conselho Federal de Contabilidade. Resolução CFC no 853. Brasília, 28 de julho de 1999.

Dias, C. M. P. (2009). A formação do professor de ciências contábeis: a importância do aprendizado para a docência. 2010. 92 f. Dissertação (Mestrado em Educação) - Núcleo de Pós-Graduação em Educação, Universidade Federal de Sergipe.

Gonzales, A. \& Ricardino Filho, A. A. (2017). Transparência na divulgação de resultados do exame de suficiência do CFC. Revista Contabilidade Vista e Revista. ISSN 0103-734X. Universidade Federal de Minas Gerais. Belo Horizonte. v. 28, n. 1.

Fonteles, I. V., Oliveira, M. C., Almeida, S. R. (2011). Medidas adotadas pelas IFES brasileiras visando a qualificação docente e a adequação de conteúdos com as novas práticas contábeis. In: $8^{\circ}$ Congresso USP de Iniciação Científica em Contabilidade. São Paulo.

Marion, J. C; Garcia, E. \& Cordeiro, M. (1999). Discussão sobre metodologias de ensino aplicáveis à contabilidade. Contab. Vista \& Rev., Belo Horizonte, v. 10, n.1, p. 28-33.

Megliorini, E.; Weffort, E. F. J. \& Holanda, V. B. (2004). Amostragem. In: Corrar, L. J., Theóphilo, C. R. (Org). Pesquisa Operacional para Decisão em Contabilidade e Administração: Contabilometria. São Paulo: Atlas, p. 19-74.

Tostes, F. P. (2008). Formação do contador: uma visão comparativa Brasil, França e Estados Unidos. Pensar Contábil, v. 7, n. 28. 